\title{
Editorial
}

\section{Celebrating the 100th anniversary of Memórias do Instituto Oswaldo Cruz}

With the current issue, Memórias do Instituto Oswaldo Cruz has completed 100 years of continuous publication in the biological and biomedical sciences. The first issue of Memórias appeared in April 1909, two years after the decision of Oswaldo Cruz, the director of Instituto Oswaldo Cruz in Manguinhos, to create a scientific journal to essentially publish the contributions of local researchers. In that first issue published in April 1909, Carlos Chagas published the discovery of American trypanosomiasis, and other important workers from Manguinhos and elsewhere subsequently also published their best contributions to science in the following issues. The Memórias quickly became an international journal and one of the most important in Latin America in the fields of parasitology, microbiology and tropical medicine.

In the late 1990s, thanks to the development of new technologies, especially electronic publishing and the internet, the Memórias became a more competitive and visible journal worldwide.

In recent years, efforts have been made to improve the quality of the journal and enhance its permeability in the world scientific scenario. Published issues have been available as online and print formats for the last 12 years, and the complete collection of other past issues, from 1909-1995, is available in PDF format. Since 2007, submission, reviewing and editing of new manuscripts have been carried out through an online system, and abstracts linked to HTML and PDF formats of published articles are rapidly in several databases, such as PubMed, Medline and Web of Science.

Consequently, a substantial increase in the number of manuscripts submitted by workers from all over the world, citations and the impact factor has been noticed over the last eight years.

The following figure illustrates the increasing interest of authors in publishing in Memórias, among which $40 \%$ are from outside of Brazil, mainly other countries in Latin America. Indeed, with the advent of the online submission system in mid-2007, a clear increase in the number of papers submitted for publication in Memórias do Instituto Oswaldo Cruz was noticed; the number of submissions per year has almost tripled in the last eight years.

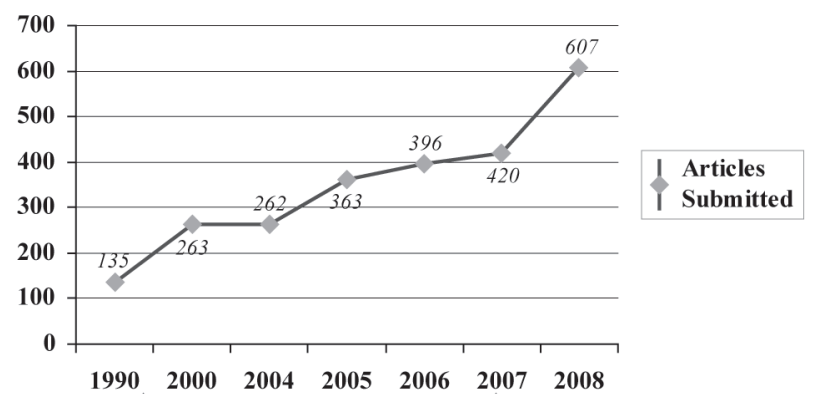

The continual increase in the Impact Factor is a result of efforts to improve the quality of research papers published in Memórias. It has attracted higher quality manuscripts and attracted good authors from all over the world, interested in submitting their original papers as well as their reviews to Memórias.

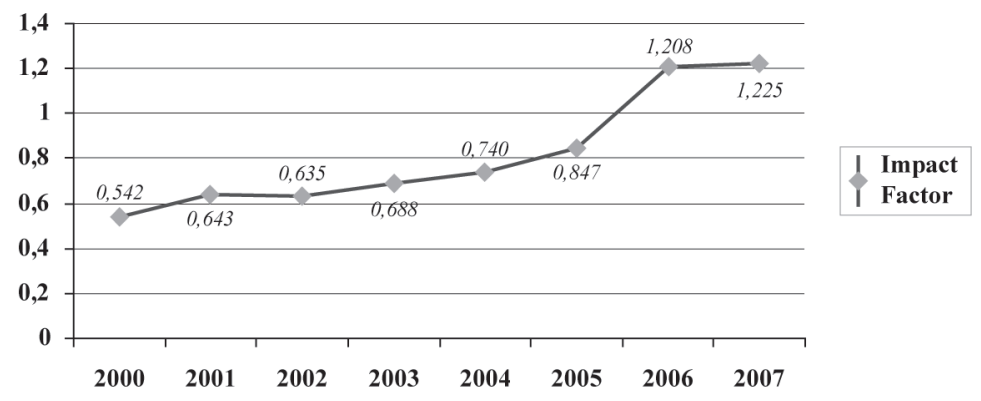

Long life to Memórias! We will continue our efforts so that this centenary and traditional scientific journal could conquer an increasing international prestige. 